\title{
Pensar la ciencia política de forma alternativa: el caso de la mexicana Paulina Fernández Christlieb
}

\author{
Thinking political science in an alternative way: the case \\ of the Mexican Paulina Fernández Christlieb
}

\author{
Odín Ávila Rojas \\ Doctor en Ciencias Sociales \\ Profesor e investigador de la Universidad del Cauca - Colombia \\ Correo electrónico: odinavila@unicauca.edu.co \\ avilaodin@gmail.com
}

\section{Resumen}

El presente artículo analiza el caso del pensamiento investigativo alternativo de la politóloga mexicana, Paulina Fernández Christlieb, quien propuso un enfoque crítico de los paradigmas de la ciencia política dominante que se basa en la democracia electoral y las políticas públicas. Este trabajo busca explicar cómo la propuesta de Fernández Christlieb se centró en analizar el concepto de izquierda y asociarlo con los debates de la autonomía y las movilizaciones antisistémicas. Su punto de partida fue la investigación que realizó sobre el movimiento zapatista en México. La metodología usada fue un análisis documental sobre lo que escribió la académica, y sobre otros textos contextuales y que apoyan la reflexión teórica e investigativa. El aporte de esta estudiosa

Cómo citar este artículo:

Ávila Rojas, O. (2021). Pensar la ciencia política de forma alternativa: el caso de la mexicana Paulina Fernández Christlieb. Revista de la Facultad de Derecho y Ciencias Políticas, 51 (134), pp. 100 - 124. doi: https://doi.org/10.18566/rfdcp.v51n134.a05

Recibido: 27 de marzo de 2020

Aprobado: 12 de noviembre de 2020 
mexicana fue abrir la ciencia política al estudio de la izquierda, la autonomía y las luchas antisistémicas, así como este tipo de trabajo, en este sentido, muestra que es posible repensar el estudio del poder y la política desde otros horizontes teóricos y de experiencias social.

\section{Palabras clave}

Ciencia política; politólogo; América Latina; gobierno; democracia; sistema electoral.

\section{Abstract}

This article analyzes the case of the alternative investigative thinking of the Mexican political scientist, Paulina Fernández Christlieb, who proposed a critical approach to the paradigms of dominant political science based on electoral democracy and public policies. This work seeks to explain how Fernández Christlieb's proposal focused on analyzing the concept of the left and associating it with the debates on autonomy and anti-systemic mobilizations. Her starting point was her research on the Zapatista movement in Mexico. Documentary analysis is the methodology used. What the academic wrote, and on other contextual texts that support theoretical and investigative reflection. This Mexican scholar contributes to the studies of the left, autonomy, and anti-systemic struggles. As well as this work, in this sense, shows that it is possible to rethink the study of power and politics from other horizons theoretical and social experiences.

\section{Keywords}

Political science; political scientist; Latin America; government; democracy; electoral system.

\section{Introducción. Un pensamiento investigativo politológico alternativo}

La tradición politológica en México, como en el resto de América Latina, se ha centrado en investigar a la democracia, los partidos, las políticas públicas y las instituciones que legitiman jurídica y administrativamente al Estado. Pero, pocos son los casos que han asumido la responsabilidad y el compromiso de estudiar la política y el poder fuera de las instituciones formales y desde las experiencias en los márgenes estatales, como lo hizo la politóloga mexicana Paulina Fernández Christlieb, quién se arriesgó a formular investigaciones críticas frente a los marcos interpretativos de las políticas públicas fundamentados en los paradigmas que se centran en el análisis institucional, cuya autores representativos y más conocidos en países como Colombia son André-Noël Roth Deubel (2002) y Elinor Ostrom (2010). 
Muestra de ello es que la mexicana, cuando era un prejuicio estudiar a los movimientos sociales desde las ciencias políticas, en las décadas de los ochenta y noventa, demostró interés en analizar a estos como sujetos que luchan por generar alternativas de organización frente al capitalismo neoliberal y el campo de disputa estatal. Más adelante, es importante mencionar que este tipo de esfuerzos hechos por académicas como la politóloga mexicana abrieron el camino en el siglo XXI para que las ciencias políticas se interesarán, aunque fuese de manera marginal, en estudiar la acción colectiva y las identidades en sus agendas investigativas.

Hay que señalar, que todavía, a finales del siglo pasado, la acción colectiva, política contenciosa (Tarrow, 1997), y el estudio de las identidades de los movimientos sociales (Melucci,1999) se asociaban al estudio sociológico, y no se pensaba que podían ser de interés politológico. Sin embargo, en la última década del presente siglo, la situación ha cambiado, al grado de que, incluso, el estudio de los movimientos sociales se ha tratado de afrontar desde la perspectiva de las políticas públicas (López Leyva, 2012) (Vélez-Rivera, 2015).

Fernández Christlieb fue una destacada investigadora de la ciencia política mexicana y latinoamericana que trabajo en la Facultad de Ciencias Políticas y Sociales de la Universidad Nacional Autónoma de México (FCPyS-UNAM), sobre cuyo legado académico no se ha escrito aún literatura especializada, con excepción de la reseña que Arturo Anguiano (2016) realizó a su último libro, titulado Justicia autónoma zapatista (2014). Nació en 1954 en la Ciudad de México y falleció en el presente año (2020) y en la misma ciudad de nacimiento, la capital mexicana. La politóloga provenía de una familia conservadora y perteneciente a la elite del país en términos políticos, y con importante impacto académico. El ser parte de esta familia le permitió tener acceso y formación universitaria sólida, pero, al mismo tiempo, la hizo entrar en conflicto ideológico con ella y generaron el paso a un horizonte de ideas que correspondieron a la izquierda marxista-leninista-trotskista y a los debates críticos sobre la democracia, los partidos y el Estado que, más adelante, hicieron que tomara distancia de la lectura militante de Marx y explorara otras fuentes ideológicas de experiencias, como la zapatista o neozapatista, en México.

Es importante explicar que el movimiento zapatista es un caso que articula la lucha indígena con la izquierda mestiza en México, cuyo objetivo, hasta el momento, ha sido la liberación y democratización nacionales. Sus fuentes ideológicas son diversas y van desde la recuperación de la cultura y cosmovisión indígenas, hasta la reivindicación de las luchas campesinas y caudillos 
rebeldes, como Emiliano Zapata. Incluso, la experiencia de los zapatistas en su largo camino por la autonomía basada en formas comunitarias indígenas de organización y gobierno propio los ha llevado a tener una postura antisistémica (Ávila-Rojas, 2019). Hay que señalar, que la posición antisistémica de los rebeldes del sureste, plantea una lucha contra el capitalismo neoliberal y que incluye la denuncia, tanto de la persistencia colonial, como del despojo, la opresión y explotación histórica sobre los pueblos de México y América Latina.

El presente artículo tiene como objetivo, por un lado, dar a conocer el trabajo investigativo de la politóloga Fernández Christlieb mediante la recuperación de sus textos principales. Por otra parte, se reflexiona sobre su pensamiento investigativo a partir del análisis de dos ideas que fueron el eje de sus trabajos: la construcción de una noción de izquierda distinta a la definida por los gobiernos progresistas del siglo XXI, que estuvo acompañada por la discusión sobre las alternativas de organización política frente al capitalismo neoliberal.

Para esto, es importante conocer algunos datos biográficos de la intelectual de izquierda, que nació en 1954 y falleció el 4 de marzo del 2020 en Ciudad de México. Petrich Blanche, periodista de La Jornada, informó el 5 de marzo del 2020 en esta publicación, que Paulina de Jesús Fernández Christlieb (su nombre completo) había muerto de cáncer y había sido encontrada sola en su apartamento. Su fallecimiento impactó tanto a la academia mexicana y latinoamericana como a las diversas organizaciones y movimientos de izquierda, como es el caso del zapatista que se convirtió en su causa durante la última etapa de su vida (2020, p.12).

Fernández Christlieb se formó como investigadora y docente universitaria en la Facultad de Ciencias Políticas y Sociales de la Universidad Nacional Autónoma de México (UNAM), una de las casas de estudio más significativas en el contexto global, en materia de producción científica. Ella, desde la década de finales de los sesenta, y en los setenta, se interesó en participar en espacios y organizaciones de la izquierda marxista-leninista, e incluso llegó a pertenecer a partidos políticos en los ochenta, por ejemplo, fue miembro del Partido Revolucionario de los Trabajadores (PRT, fundado en 1976).

Hay que señalar, que las izquierdas marxista-leninistas se preocuparon por tratar de llevar a la práctica el pensamiento marxista como guía y estrategia para la organización revolucionaria de la acción colectiva. De ahí se desprendieron diversas corrientes como la trotskista, la maoísta, la estalinista, entre otras. La 
politóloga mexicana se formó con sustento en un capital cultural e intelectual nutrido en gran parte por los marxismo-trotsquismos y se convirtió en una gran lectora de las obras clásicas del materialismo dialéctico e histórico y de los estudiosos relacionados con los debates marxista-leninistas de autores como Ernest Mandel (1923-1995), quien fue uno de los intelectuales e ideólogos trotskistas más importantes del siglo pasado.

En estas décadas, el régimen del priismo dominaba la forma, el sistema y la lógica democrática en México de manera autoritaria y en el que su funcionamiento dependía exclusivamente del gobierno de un partido y no de una pluralidad política que era negada, marginada o usada para legitimar la llegada a la presidencia de los distintos candidatos priistas. En este contexto, Fernández formuló su crítica a la democracia y al modelo partidista electoral y profesional, porque identificó que la idea de una oposición de la izquierda frente al priismo era bloqueada 0 limitada mediante mecanismos administrativos y jurídicos que eran diseñados para que la ciudadanía y los mismos partidos en la competencia electoral no pudiesen exigir, de manera efectiva, la revisión de fraudes y condiciones más igualitarias y justas en la lucha por el poder político en el país.

Más adelante, con la puesta en vigor del Tratado del Libre Comercio, en la década de los noventa, Fernández enfrentó otro tipo de escenarios políticos en los que la crítica a los partidos y a la democracia pasó a estar mucho más en la arena de las luchas de movimientos, como fue el caso del zapatismo. La irrupción pública de este movimiento fue en 1994 y provocó que la misma izquierda mexicana, e incluso latinoamericana, se deconstruyera en términos de sus objetivos y medios de lucha.

Por supuesto, este tipo de experiencias influyó en que la politóloga repensará su idea de izquierda en una dimensión ya no solo en la lógica de los partidos políticos e ideologías marxista-leninistas, sino en otros marcos de acción y organización colectiva, como las movilizaciones con un discurso antisistémico y con demandas alrededor de la construcción de la autonomía territorial y el reconocimiento de derechos de la diversidad cultural y étnica.

En este sentido, la hipótesis que guía este trabajo es que la investigación de la mexicana se basó en una preocupación por pensar a la ciencia política desde paradigmas alternativos y que rompieran con tabúes dentro de ella, por ejemplo, la discusión para definir a la izquierda a partir de las experiencias que la mexicana consideró que eran alternativas organizacionales al capitalismo neoliberal y al sistema político democrático electoral (2006). Su punto de 
partida de análisis no fue identificar a la izquierda a partir del principio clásico, que es una corriente opuesta a la derecha y basada en la defensa de la libertad y la igualdad, sino, más bien, que su propuesta se fundamenta en considerar a la experiencia social y política desde los mismos movimientos sociales como referente que marca la diferencia entre la noción tradicional y la actual. Por lo tanto, pone a discusión el término de izquierda fuera de los marcos ideológicos del liberalismo, del marxismo-leninismo e inclusive, de la lógica de ubicar únicamente a dicho término dentro de los progresismos del siglo XXI.

Por eso, se planteó desarrollar lo anterior mediante los siguientes apartados: apuntes metodológicos; la izquierda como noción surgida de la experiencia social; gobierno autónomo y antisistema político como ejes de construcción de las alternativas de organización política, y finalmente: debates y conclusiones.

\section{Apuntes metodológicos}

La metodología de este artículo se basa en un análisis documental sobre lo que escribió Paulina Fernández y aquellos textos que aportaron a sus temas de investigación. Es de observar que la politóloga mexicana, en una primera parte de sus trabajos sobre partidos, democracia y las izquierdas, hizo una recopilación, análisis y sistematización de la información, tanto cualitativa (archivos, artículos especializados, libros, tesis y diversos tipos de textos políticos e ideológicos elaborados por los mismos integrantes de las organizaciones y movimientos) como cuantitativa (el procedimiento basado en la construcción de datos y cifras que no estaban dentro de los cálculos oficiales de las instituciones y que incluso las contrastaba con estas últimas) a partir de documentos y textos con contenidos relacionados al tema estudiado.

Luego, la autora, en una segunda parte de su investigación, toma distancia de este método y se abrió a experiencias mucho más cercanas a la práctica misma de la construcción del autogobierno, la autonomía y sistemas políticos alternativos al modelo de Estado moderno. Su dependencia con la teoría cada vez fue menos para explicar los marcos conceptuales en sus trabajos.

La propuesta metodológica de Fernández Christlieb estuvo ligada a su experiencia y tránsito por la política y el estudio de esta, por ello, se pueden distinguir dos etapas en términos de sus objetivos: la primera, que estaba centrada de manera crítica en analizar los partidos y la democracia; y la segunda, que se enfocó en investigar a sujetos políticos y sociales como los zapatistas. En este 
artículo, ambas etapas se consideran, pero, a diferencia de la académica estudiada, este es un trabajo escrito fundamentalmente basado en el análisis documental de sus cinco libros, que son: El espartaquismo en México (1978), La clase obrera en la historia de México en el sexenio de Tlatelolco (1964-1970) (1985), La marcha del EZLN al Distrito Federal (2001), EI EZLN y la GBI en Chiapas: derechos indígenas contra corporaciones trasnacionales (2003), Crisis de la democracia electoral (2006), Justicia autónoma frente a justicia oficial (2012), y su última obra, Justicia autónoma zapatista en la zona selva Tseltal (2014).

También se hizo una revisión de las plataformas de Scielo, Red de Revistas Científicas de América Latina, el Caribe, España y Portugal (Redalyc), Red de Bibliotecas del Consejo Latinoamericano de las Ciencias Sociales (CLACSO), Jstor y documentos programáticos de movimientos, como el zapatista que ella estudió. Además, se revisó la base de datos de la Biblioteca de la Universidad Nacional Autónoma de México y otros archivos de fuentes escritas en México y Colombia.

El análisis documental fue aplicado en la elaboración de este artículo mediante los siguientes pasos metodológicos: primero, se hizo la síntesis como operación metodológica y procedimiento para analizar el contenido de las fuentes documentales; segundo, se adelantó la categorización y agrupación conceptuales de las ideas contenidas en la información investigada para la elaboración de la cartografía y esquemas que permitieran la organización y desarrollo de cada uno de los apartados del artículo, y; tercero, luego de aplicar un criterio de ordenamiento a las categorías, se pasó a explicarlas con base en la información documental (Hernández, Guerrero \& Tobón 2015).

\section{La izquierda como noción surgida de la experiencia social}

Después de haber hecho una revisión de los trabajos principales de Paulina Fernández Christlieb, se puede identificar que la visión para analizar a la izquierda que propone esta autora busca superar la ambigüedad del término. Su ruta para hacerlo se basa en su experiencia investigativa y militancia política en las luchas sociales de las últimas décadas del siglo $\mathrm{XX}$ y las primeras décadas de la presente centuria. Fernández, primero, en su texto El espartaquismo en México (1978), definió a la izquierda desde un criterio que recupera a la clase trabajadora como el referente ideológico de quienes deben guiar la transformación social. 
Incluso, cuando la autora habla de "espartaquismo", indica que "hay una masa trabajadora que llegará a tener sus propios ritmos de luchas fuera del mismo Partido Comunista” (1978, p. 10). Es importante señalar, que el espartaquismo fue un movimiento político alemán de carácter socialista, que más tarde se convirtió en comunista y agrupó a algunas minorías socialdemócratas, al igual que tuvo su impactó en diversos casos latinoamericanos.

A partir de estas experiencias, ella definió a la izquierda fuera de los límites de los partidos, y en un marco interpretativo distinto al tradicional, que consiste en que su eje de caracterización son las posturas ideológicas que defienden la igualdad y la distribución de la riqueza por encima de la justicia y otros principios político-sociales (Bobbio \& Matheucci, 1985; Bobbio, 1995).

A diferencia de la tradición politológica de Bobbio y Matteucci, Paulina Fernández piensa que la izquierda debe entenderse como un fenómeno ideológico que se encuentra sujeto al cambio histórico y a la diversidad de manifestaciones que giran en torno a dos principios, que son la ética del anticapitalismo y el cuestionamiento radical a las instituciones políticas que reproducen y legitiman las relaciones de poder del status quo. La politóloga mexicana aplicó ambos principios a sus estudios al identificar distintos sujetos que ella consideró siguen la ética anticapitalista y expresan una crítica al status quo como por ejemplo la clase trabajadora mexicana de la década de los sesenta, setenta y ochenta del siglo pasado.

Fernández Christlieb, en uno de sus textos, La clase obrera en la historia de México, que elaboró con Octavio Rodríguez Araujo, postuló a los sindicatos y a las luchas de los trabajadores como un posible punto de origen de esta ética anticapitalista para la izquierda (1985, p. 25). El criterio de los dos autores fue la clase social explotada en las relaciones de producción y el capitalismo lucha por liberar su consciencia en términos ideológicos del status quo. Hay que señalar que en el caso mexicano, los trabajadores en esa época estaban organizados dentro del Estado, pero representaban una fuerza política masiva que, según la politóloga mexicana, junto con el libro que escribió con Rodríguez Araujo, si lograban su independencia del control gubernamental desde lo estructural, podían generar un cuestionamiento al orden institucional formal.

Es importante matizar esta idea y redimensionarla en el tiempo, porque dicha clase se constituyó finalmente en México dentro de los parámetros del PRI, pero no logró su autonomía como sujetos políticos propios. La clase obrera mexicana, incluso en el siglo XXI, no solo se corporativizó, sino que, 
además, se fragmentó y profundizó sus contradicciones con los grandes capitales trasnacionales. La idea de la clase trabajadora como eje central de las luchas de las izquierdas que sostuvo esta politóloga se debe a que, en esa época, el trotskismo recuperaba un postulado marxista clásico, que es el de la centralidad política del proletariado (Marx \& Engels, 2007).

La centralidad política del proletariado fue una idea planteada por Carlos Marx y Federico Engels (2007) a mediados del siglo XIX, en la que identificaron que los trabajadores de las fábricas industriales en Inglaterra no estaban constituidos como sujetos políticos autónomos, porque, su dimensión ideológica y consciencia estaba subordinada a los patrones, mecanismos y estrategias de alienación y enajenación de las relaciones capitalistas. Ambos pensadores caracterizaron a esta problemática como el proceso de constitución política que enfrenta el explotado para ser un sujeto autónomo frente al capitalismo.

Un proceso contra la enajenación y la alienación del proletariado al capitalismo. El primero hace referencia a la situación en la que un individuo no tiene consciencia de sí mismo como sujeto, es decir, se encuentra alienado a una relación de poder estructural en los ámbitos de la economía, cultura, política y social que lo cosifica. La cosificación entendida, en este caso, como el proceso de objetivización de las relaciones sociales mediante el capital (Marx, 2017). Mientras, la segunda, es la alienación entendida como la cosificación individual del sujeto, en tanto que es reducido a mercancía de intercambio en el capitalismo. El oprimido, desde Marx y Engels, se encuentra en constante lucha, tensión, conflicto, antagonismo y contradicción para definir colectivamente su identidad, destino, forma de vida y proyecto político como sujeto integrante de una clase social que busca su emancipación frente al capitalismo.

En esta etapa de sus investigaciones, la politóloga postuló que el proletariado organizado en su formato "partido político", con objetivos revolucionarios, podía lograr la emancipación de la clase trabajadora en México, como en el resto del mundo (2006, p.30). Su investigación, en ese momento, partía del principio trotskista de pensar que la estrategia revolucionaria consistía en internacionalizar la lucha obrera y extenderla en los diversos países en profundas condiciones de explotación, despojo y opresión. En seguimiento con esta idea, el sujeto autónomo portador de la ética revolucionaria y capaz de cuestionar las contradicciones y antagonismos del capitalismo es la clase obrera organizada en partido político. 
Más adelante, la investigadora mexicana llega a la conclusión de que la clase obrera mexicana, en realidad, no puede ser ese sujeto ético y cuestionador que puede ser recuperado como referente para analizar la izquierda crítica y antisistémica, porque aunque el proletariado ha sido pieza fundamental en la construcción del Estado mexicano con sus alianzas de clase, fue cooptado por el sistema político, por lo menos en su mayoría, sin dejar que tuviese una organización autónoma frente a las oligarquías del país.

Pensadores como el boliviano René Zavaleta Mercado (1990, 2009), entre otros teóricos latinoamericanos emblemáticos del siglo pasado, han explicado que la construcción estatal en América Latina depende de la capacidad de articulación entre las diversas clases sociales y sectores; sin embargo, eso es en un principio, luego de ello, las clases dominadas tienen que buscar su propia organización y estrategia para definir su centralidad frente a las instituciones políticas formales, porque corren el riesgo de ser absorbidas por el sistema y la izquierda que trata de influir en ellas se queda sin un sujeto crítico y lo sustituye por una versión domesticada o simplemente con la neutralización de su accionar político.

Este fenómeno fue estudiado por la politóloga mexicana, cuya observación la llevó a identificar que el centro de gravedad que definía a las posturas de izquierda ya no eran necesariamente la ideología y consciencia de clase proletarias, ni tampoco los derechos liberales planteados únicamente desde los formatos de los partidos políticos tradicionales. El nuevo centro, en este sentido, son los movimientos sociales reivindicadores de aspectos identitarios étnicos y con demandas enfocadas en los debates de la autonomía (Pleyers, 2018), que comenzaron a constituirse en una dimensión nacional e internacional, como en el caso mexicano, a partir de la década de los noventa. Contexto en donde los zapatistas han sido un paradigma de esta izquierda y usados por la académica como referente de identificación el siglo XXI.

La postura de la autora discute con el enfoque de los nuevos movimientos sociales y acción colectiva, de autores como Alberto Melucci (1999), que parten de la idea de que la identidad es el centro de la lucha y organización de la ciudadanía, sin considerar la importancia de los procesos autonómicos y las experiencias antisistémicas. La autonomía, el antisistema político y la democracia se convirtieron en el eje de la discusión que planteó la mexicana para explicar las luchas sociales y la manera en que la acción colectiva se puede transformar en alternativas políticas de izquierda frente al capitalismo. 
Su definición de izquierda, en este sentido, parte de dos procesos históricos, políticos y sociales de México y América Latina: el primero, es que la noción tradicional de asociar a la izquierda con los principios socialistas y comunistas del siglo XX y que nutrieron en gran parte sus contenidos ideológicos perdieron su significado con el ascenso de gobiernos progresistas en distintos países latinoamericanos en los que, como dicen Massimo Modonessi, Franck Gaudichaud y Jeffery Webber, hubo una combinación de fuerzas y movilizaciones sociales, agendas de corte progresistas y un intento de dominar el neoliberalismo, sin eliminar sus contradicciones y antagonismos por parte de quienes ocupan los cargos gubernamentales (2019).

Es importante explicar que, según estos autores, el progresismo propiamente no es una corriente de izquierda, pero se asoció con esta al grado de crear una confusión. Incluso, estos autores aclaran que el progresismo es el conjunto de

los programas y las fuerzas sociales y políticas socialdemócratas, populistas o nacional-populares, que buscaban transformar y reformar al capitalismo introduciendo dosis de intervención y regulación estatal y de redistribución de la riqueza: en el caso latinoamericano, con un nítido acento antiimperialista y desarrollista. Este último aspecto, ahora presentado como neodesarrollismo, se conecta con la noción de progreso y contribuye a definir el horizonte y el carácter del proyecto, así como de las críticas que, desde perspectivas ambientalistas, ecosocialistas o poscoloniales, cuestionan frontalmente la idea de progreso y la de desarrollo tanto en sus expresiones de los siglos pasados como en su prolongación en el siglo XXI. (2019, p.9).

En este sentido, la idea de progresismo que manejan estos autores contribuyen al argumento de la investigadora mexicana, en el que esta separa aquellos progresismos del término de izquierda, porque los primeros responden a un proceso y expectativas de movimientos y organizaciones sociales sobre gobiernos integrados por aquella gente que, en algún momento, simpatizó activamente, militó e incluso se autoproclama de izquierda. Mientras al hablar de izquierda, como lo postula esta politóloga, es un concepto que está mucho más ubicado en las disputas ideológicas de los programas que cuestionen el orden económico, político y social, al igual que a partir de estos sean planteados proyectos alternativos.

El segundo proceso que identifica la politóloga mexicana se relaciona de cerca con los escenarios nacionales y la percepción social sobre los partidos 
políticos electorales que ella analizó en México. Para Fernández Christlieb, los partidos, como modelo alternativo de representación y participación democrática, han perdido cada vez más validez, porque son vistos por la ciudadanía como únicamente un mecanismo o camino de llegada al poder político, sin una legitimación social necesariamente.

Hay que entender que esta autora enmarca su idea de izquierda en un contexto y época en los que los partidos y el sistema democrático de países como México entraron en una crisis de legitimación en términos de representación electoral, y que abarcó gran parte del siglo XX y que, inclusive no ha terminado, porque la ciudadanía, desde esa época, cuestionó el papel de la representación de las instituciones responsables de vigilar y llevar a cabo los procedimientos de votación y legislación; es decir, dejó de confiar en ellas. Sin embargo, no toda la ciudadanía optó por abstencionismo en relación con el voto, aunque eso no implicó que la desconfianza y que la desconexión entre partidos y sociedad dejara de profundizarse al grado que las nuevas generaciones cada vez menos creen en que los partidos pueden ser un modelo de organización efectiva de representación y participación que busca el bienestar, la igualdad, la justicia y la defensa de las demandas sociales.

La investigadora mexicana, en su texto, Crisis de la democracia electoral, precisamente menciona lo siguiente:

en las manifestaciones políticas del modelo de dominación hay que añadir las bases económicas sobre las cuales se edificó, para comprender que el capitalismo -de suyo excluyente de los más-, ha agravado la situación del grueso de la población mundial durante las décadas de la globalización neoliberal, al tiempo que proclama y exalta el triunfo indiscutible de la democracia. El régimen político que escogió la elección como el eje de su concepción y práctica de democracia está hoy en crisis, entre otras razones, porque el llamado "Estado benefactor", que en los últimos tiempos le ayudaba a ocultar su verdadera naturaleza, en esencia y en los hechos no existe más. (2006, p.26).

Por eso, esta politóloga explica más adelante que la democracia electoral se ha convertido en la unión de una serie de mecanismos que legitiman el capitalismo. De ahí que ella, en una cita, dice que,

ello no afecta al capital ni impide su reproducción, ni frena la acumulación, ni limita la concentración del dinero mundial por unas cuantas personas, al 
contrario, su democracia, la democracia representativa se lo garantiza, a tal punto que hasta tolera el arribo de partidos y personajes "de izquierda" al gobierno de países en los que antes interpuso dictaduras militares para evitarlo. (2006, p. 26)

Fernández se refiere a que la izquierda, cuando llega al poder por vías electorales, realmente no lo hace mediante un sistema democrático como tal, porque ella argumenta que dicho proceso más bien corresponde a

la crisis de la democracia electoral -que no es democracia ni es representativa- encuentra su máxima evidencia en la piel de los pueblos, en las experiencias familiares, en la vida cotidiana de los trabajadores del campo y de la ciudad. El capitalismo actual, con los resultados inconfundibles del neoliberalismo, confirma día a día a los millones de pobres, miserables, migrantes, explotados, en fin, a los excluidos en todas partes del mundo, que quienes deciden por ellos, que quienes gobiernan en su nombre, no los representan; ni siquiera toman en cuenta su existencia. (2006, p.26).

La visión de la politóloga mexicana discute con la perspectiva de los transitológos clásicos, como Guillermo O Donnell y Paul Schmitter (1986) y Marcelo Cavarozzi (1992), quienes, en común, plantean que la izquierda y la derecha son posiciones que se expresan en las contiendas electorales y que continuamente son expresadas por los partidos y el sistema democrático, donde en cada lucha por la presidencia existen ambas posturas de una u otra forma entre los aspirantes. Los transitológos piensan a la izquierda y a la derecha dentro del espectro partidista, por lo tanto, para ellos, los primeros defienden la igualdad sobre la libertad y la justicia, y los segundos, a la inversa.

El problema es que la izquierda y la derecha, para los transitológos, son posiciones políticas e ideológicas dentro de un sistema democrático, sin considerar que históricamente ambas posturas tienen trayectorias complejas y que se han consolidado, incluso, fuera de las instituciones democráticas. Ejemplo de ello son las sociedades modernas latinoamericanas, en las que la democratización es un proceso externo a las mismas instituciones formales estatales, las cuales han cumplido una función de apertura al sistema político dominante, como lo menciona el politólogo chileno, Helio Gallardo (2007).

Contrariamente a lo que esta tradición plantea, la académica de la UNAM postula que la izquierda debe ser analizada como un concepto que depende de su contexto, trayectoria histórica y proceso social al que se inscriben quienes 
se identifican con esta. Hay que entender que esta autora enmarca su idea de izquierda en un contexto, por un lado, en el que los partidos políticos y el sistema democrático de países como México entraron en una crisis de legitimación en términos de representación electoral que abarcó gran parte del siglo XX y comienzos del presente, porque la ciudadanía ha dejado de confiar en las instituciones responsables de vigilar y llevar a cabo los procedimientos de votación y legislación, al igual que se ha profundizado una desconexión entre los partidos y la sociedad.

Una desconfianza que se ha traducido en una desilusión sistemática que ha ido en aumento, a pesar de que ha habido procesos como las elecciones del 2018 en las que la llegada por vías democráticas y legitimadas por una masiva votación y movilización ciudadana inédita en este país, por parte de Andrés Manuel López Obrador (AMLO), significó una esperanza contra la corrupción del sistema político dominado por "la forma de hacer política priista". El priismo fue una forma de hacer política clientelar y corporativa que impulso el PRI durante más de 70 años para el funcionamiento institucional del Estado mexicano en el siglo $X X$, y que en la actualidad sigue vigente en los partidos, e incluso, en la manera en que se regulan los distintos tipos de autoridad política en el país.

Por ejemplo, la ideología de izquierda generada alrededor de la movilización contra el fraude electoral que le hizo el sistema político a AMLO, tuvo como rasgos una combinación de la recuperación de una tradición nacionalista, la reivindicación y ejercicio de la figura liberal social ciudadana en los procesos democráticos con una postura progresista, que es adaptable a los cambios de la economía capitalista neoliberal. Una izquierda que, pese a que surgió en una coyuntura en la que hubo un cuestionamiento al sistema, y donde fue organizado un Movimiento de Regeneración Nacional (MORENA) -que tuvo una postura radical contra la corrupción, el clientelismo y las instituciones democráticas-no derivó en la transformación estructural del Estado mexicano.

MORENA, pese a sus esfuerzos, tampoco logró producir su propia autonomía organizativa y rebeldía frente a la dirección del movimiento, y que, finalmente, se convirtió en un partido político bajo el formato electoral y tradicional que tanto había cuestionado el mismo movimiento. Pero que AMLO, tanto por su objetivo -que fue la conquista del poder del Estado-, como por estrategia política propia, optó por entrar al juego electoral.

Jaime Osorio (2015) y Carlos Antonio Aguirre Rojas (2018), influidos por el debate planteado por Immanuel Wallerstein (2005) sobre la relación entre 
movimientos sociales y el sistema-mundo capitalista, catalogan a este tipo de izquierda como sistémica, porque, según estos académicos, no hace una crítica radical al sistema capitalista mundial, ni tampoco hay un pronunciamiento explícito que identifique a las relaciones económicas dominantes como un obstáculo para la representación y participación, tanto en la lucha, como en la autolimitación del poder político.

Hay que señalar que autores como Wallerstein sostienen que la economía mundial se ha estructurado desde hace ya 500 años, y que emergió del agotamiento de un régimen previo de imperio-mundo que había sucedido a los modelos locales y regionales de subsistencia (minisistemas). A esta economía global le denomina el teórico estadounidense como sistema-mundo capitalista, cuyo rasgo es que subordina a las sociedades periféricas a centro de poder económico y político.

Por eso, a pesar de las grandes movilizaciones alrededor de MORENA, que acompañaron a esta organización producto de un proceso y lucha democrática, no fue suficiente para que la politóloga caracterizara a este caso dentro de los parámetros de la izquierda, porque no logró generar un cuestionamiento radical a las instituciones, ni tampoco hizo que AMLO planteará una ética anticapitalista, al contrario, los objetivos de su gobierno se separaron del cambió histórico que representaba su triunfo en términos democráticos y se concentró en políticas adscritas al progresismo. Muestra de ello es que el gobierno de AMLO ha sido catalogado como progresista y asociado al discurso de la izquierda enmarcada en la competencia electoral, en contraste con la visión y experiencia de movimientos como el zapatista, que cuestiona la vía institucional y los mecanismos de representación y participación presuntamente democráticos planteados desde el Estado mexicano.

Precisamente, Fernández Christlieb, durante este proceso, llegó a la conclusión de que la experiencia zapatista estaba mucho más cercana a la noción de izquierda que el mismo lópezobradorismo. Además, su visión rompe con la idea y el prejuicio de que todas las movilizaciones sociales se quedan en el marco ideológico de la izquierda, cuando no necesariamente es así. La experiencia que la académica tuvo a lo largo de su vida consistió en tener una cercanía y participación estrecha con los movimientos sociales que la llevó a pensar que la izquierda, al ser un concepto que básicamente se discute desde una dimensión subjetiva de la política, también tiene elementos que influyen en la materialización de los proyectos políticos de las poblaciones. 
No es que Fernández inventara la noción de izquierda desde las luchas sociales, sino que llevó las enseñanzas e influencia de debates de autores como José Carlos Mariátegui (2007) y Antonio Gramsci (1980) a una ciencia política alternativa a los paradigmas centrados en políticas públicas y la democracia electoral. Las enseñanzas de autores como Mariátegui y Gramsci son que la ideología, la religión, la cultura y otros elementos subjetivos tienen un impacto grande en la acción y organización de las colectividades. Por esa razón es que la politóloga pone la noción de izquierda en un nivel subjetivo, y en el que sus significados, para ella, continuamente están asociados con la acción y organización de lo colectivo y la manera en que las sociedades experimentan y perciben la cultura, la religión y, en general, el imaginario sobre los procesos políticos y hechos históricos.

Como ha sucedido con el zapatismo, en el que imágenes de la Virgen de Guadalupe (con pañuelo) o el pasamontañas, e incluso la estrella roja, se han convertido en un conjunto de simbolismos que también han nutrido el imaginario de la izquierda, en especial, aquella que se identifica con la experiencia del movimiento de los rebeldes del sureste chiapaneco. Este caso lo tomó Fernández como muestra para pensar la ciencia política desde otro horizonte teórico y experiencia que no fuesen únicamente los partidos, las políticas públicas y otros centros de gravedad conceptuales que, aunque son muy importantes en términos académicos y sociales, no son los únicos que existen para repensar la propia ciencia política.

\section{Gobierno autónomo y antisistema político como ejes de construcción de las alternativas de organización política}

Fernández Christlieb, al pensar a la izquierda como concepto politológico y eje de su pensamiento investigativo, también hace una asociación con otras dos ideas que son gobierno autónomo y antisistema político, cuyos términos adquieren una dimensión principal en la construcción de alternativas de organización política. Además, cuando la investigadora usa las ideas de gobierno autónomo y antisistema político para caracterizar a la izquierda actual, al mismo tiempo, a través de ellas, logra diferenciar a estas experiencias en términos ideológicos de las derechas. Su punto de partida y caso estudiado es el movimiento zapatista, que irrumpió en escena pública en Chiapas, México, en 1994. 
El zapatismo es un movimiento que, en resumidas cuentas, ha luchado contra el despojo, la explotación, la opresión y el racismo que existe en el sureste mexicano. Su lucha se ha extendido al territorio nacional e, incluso, ha tenido un eco internacional en la opinión pública, al igual que las diversas organizaciones y movilizaciones que han tomado la rebeldía de los zapatistas como símbolo y referente en el imaginario tanto de estas como de las izquierdas contemporáneas. La rebeldía zapatista logró conectar las experiencias de luchas sociales del siglo XX con distintas expresiones de movilización en el presente siglo mediante su ejercicio de autonomía y autogobierno insertado en contexto de extrema violencia, despojo y extractivismo, hechos que fueron identificados por Fernández Christlieb $(2001$; 2003) como una manera alternativa de practicar la ciencia política en sociedades complejas.

Sociedades complejas como las de México y América Latina, en las que la diversidad cultural y étnica son componentes atravesados por las desigualdades, injusticias y relaciones de poder que impiden su desarrollo autónomo. Frente a ello, los zapatistas han respondido con una propuesta alternativa de organización de la política y el poder a lo largo de más 26 años de su resistencia. Su propuesta consiste básicamente, por un lado, en una estrategia ideológica de izquierda que organice a las diversas clases, sectores y grupos marginados, excluidos, oprimidos y subalternizados por el capitalismo neoliberal, es decir, es el abajo y a la izquierda que se convirtió en la frase de convocatoria política de los zapatistas.

Por otra parte, el zapatismo postula, como alternativa a los partidos y las instituciones formales del Estado mexicano, un tipo de organización política sustentada en lazos comunitarios, en el que exista autonomía y democracia al mismo tiempo mediante el ejercicio y práctica de quienes la conforman. Los zapatistas, a través de sus documentos políticos básicos, han enunciado que el autogobierno y la democracia comunitaria son los ejes de estructuración de su propio proyecto y centralidad política (Ávila, 2020) en oposición al modelo electoral de representación y participación que usa el capitalismo en las sociedades modernas latinoamericanas para su reproducción. Las declaraciones de la Selva Lacandona(2000, 2000a, 2000b, 2000c y 2005) son documentos que ayudan a entender el desarrollo de la propuesta política de los zapatistas desde su irrupción pública y hasta las iniciativas de La Sexta, La Otra Campaña y otros esfuerzos actuales.

Hay que señalar que la idea de centralidad política fue planteada, por primera vez, por Marx y Engels a mediados del siglo XIX, y que escribieron 
en 1848 el Manifiesto del Partido Comunista (2007). Ambos pensadores postularon que, cuando el proletariado se asumiera como clase trabajadora liberada de la enajenación y alienación capitalistas, podía constituirse como sujeto colectivo autónomo. Más adelante esta idea fue trabajada por diversos autores relacionados con los debates de la teoría política y social, entre los que destacan los zapatistas a partir de su propia experiencia, en la que ellos enuncian que el sujeto de su centralidad deben ser los mismos pueblos indígenas, sin que una organización o grupo de la izquierda mestiza les diga qué tipo de estrategia y camino de lucha deben seguir, como si fuesen menores de edad en términos políticos (Ávila, 2018; 2019; 2020).

La politóloga mexicana propone analizar el proyecto zapatista y la tendencia de la izquierda bajo los conceptos de gobierno autónomo y antisistema político. Conceptos que ella comenzó a reflexionar en una ponencia que impartió en el Primer Coloquio Internacional In memoriam Andrés Aubry, entre finales del 2009 y principios del 2010, en la Universidad de la Tierra, Chiapas ${ }^{1}$. Su ponencia fue resultado de su trabajo con las bases de apoyo y autoridades autónomas zapatistas de comunidades, municipios y Junta de Buen Gobierno de la Zona Selva Tseltal, Chiapas, México, en el transcurso del 2009.

El trabajo que realizó Fernández Christlieb, en realidad, no se había hecho desde la ciencia política, porque la etnografía y el estudio de campo, por lo general se asocian a la antropología y sociología. Los antecedentes de este tipo de estudio pueden ser rastreados en la propuesta de investigación de acción participativa (IAP) que Orlando Fals Borda (2019) y otros autores han planteados en los diversos campos de producción interdisciplinaria del conocimiento humano y social. La IAP fue la propuesta metodológica de Fals Borda para que el investigador se comprometiera y fuera parte del proceso estudiado, y en el que la teoría ocupa un segundo lugar frente a la acción y práctica comunitarias.

Fernández, en su libro titulado Justicia autónoma zapatista en la Zona Selva Tseltal, precisamente trata de ampliar la visión sobre el estudio de la realidad que se hace desde la ciencia política, al no limitarse a los métodos de recolección de información, que se limitaban a encuestas, entrevistas y recuperación de datos cuantitativos (estadísticos), porque incorpora la

\footnotetext{
1 Andrés Aubry (1927 - 2007) fue un sociólogo y activista francés con una mirada indigenista sobre los pueblos indígenas en Chiapas. Gran parte de sus intereses investigativos se centró en la experiencia comunitaria zapatista.
} 
dimensión subjetiva de los individuos estudiados, mediante la escritura de la voz de quienes han conformado las experiencias comunitarias, en este caso, de los zapatistas (2014).

La académica mexicana, al igual que Fals Borda, llevó a cabo un esfuerzo investigativo que buscó la recuperación de las voces colectivas y las iniciativas sociales y políticas de las comunidades estudiadas. De ahí que la autora expuso, que la idea de gobierno autónomo se caracteriza por plantear que "la comunidad es el actor colectivo que ejerce el poder político" (2009). Si la comunidad no se asume, ni reconoce bajo la noción de actor colectivo de sus propios asuntos comunes, entonces, el ejercicio y práctica de la política no se hacen en una condición de autonomía.

Luego, la investigadora explica que la idea de gobierno autónomo que se tiene presente en casos como el de los pueblos zapatistas consiste en

una vida comunitaria en la que la democracia no solo se refiere a elección de autoridades que son gobierno, sino que es un ejercicio permanente vinculado a la práctica cotidiana de los responsables de todos los cargos que la comunidad necesita para organizarse, para producir y reproducirse como pueblos indígenas, como seres humanos. (2009, p.2)

La autora agrega que esto es así, “complementariamente al ejercicio de la autonomía” (2009).

La razón que menciona la politóloga sobre la importancia de la autonomía y su vinculación con la democracia es porque

estas mismas comunidades conciben la democracia como un derecho del cual se deriva la posibilidad de defender otros derechos, y con ellos exigir a las autoridades que trabajen buscando el bienestar colectivo en todos los aspectos de la vida comunitaria, incluido el cuidado de la naturaleza. (2009, p. 2.

La académica mexicana parte de la idea que las comunidades, en especial las indígenas, han desarrollado lazos comunitarios que históricamente les permitieron a estas ser distintas de la lógica política de las sociedades mestizas modernas latinoamericanas, porque sus objetivos de bienestar se centran en el cuidado del medio ambiente, los recursos naturales, el trabajo conjunto, no individualizado y la resistencia a la modernidad capitalista. 
Hay que señalar que la democracia y la autonomía fueron identificadas por Fernández Christlieb como dos términos que se retroalimentan y que su coexistencia se justifica en el desarrollo de la vida comunitaria. Ambos términos fueron pensados por la académica mexicana no solo en una escala local y regional, sino también en una dimensión nacional que puede adquirir la sociedad si logra tejer lazos colectivos y de solidaridad. En este caso, es importante mencionar que los procesos democráticos, para la pensadora, conducen a la autonomía de las sociedades y a su capacidad de autogobierno.

Por esta razón, esta investigadora postula que la izquierda, en estos tiempos, al ser crítica del sistema económico y político dominante, se orienta a este tipo de experiencias en las que hay una forma de hacer política comunitaria, autónoma y democrática, para autolimitar el empoderamiento de grupos y élites. La autolimitación de las relaciones de poder aparece como condición necesaria para que se genere una relación alternativa a la modernidad capitalista en la actualidad.

Para Fernández, la autonomía se concibe como esa capacidad de la colectividad para generar gubernamentalidad y justicia sobre sí misma y de manera soberana. Idea que es expresada en su único artículo indexado que se tiene registro en las plataformas, Justicia autónoma frente a justicia oficial (2012); mientras el autogobierno es vinculado más con el ejercicio de autoridad y toma de decisiones que hay sobre la base material y las relaciones sociales en una comunidad especifica. Sin autonomía no hay autogobierno. La intelectual mexicana observó que el autogobierno, como la autonomía, por lo menos en el caso zapatista que ella investigó, tiene su legitimación en la recuperación de elementos subjetivos y complejos que operan en la mentalidad colectiva, como son los históricos, simbólicos e imaginarios culturales que han permitido que la misma comunidad administre su autonomía, así como quienes la integran se constituyan como sujetos autónomos en el campo de la disputa por el poder político en el Estado.

En el caso de los zapatistas hay precisamente una idea que consiste en plantear la relación de autogobierno con la práctica del mandato en términos democráticos del poder, al igual que la producción horizontal de dicho ejercicio. El ejemplo de los rebeldes del sureste influyó a la izquierda y las luchas sociales que se han alimentado con la idea de que la autonomía y la generación de alternativas antisistémicas son posibles.

De ahí que la autora plantée la categoría de antisistema político para hacer referencia a ese conjunto de niveles de autoridades, instituciones autónomas y, 
en general, autogobierno, que tiene control sobre el territorio en el que habita la comunidad (2014). Hay que señalar que Fernández Christlieb fue la primera investigadora que se dedicó a construir y a trabajar la categoría de antisistema político a partir de su experiencia en las comunidades zapatistas y que, luego, hubo intentos fallidos, como el que hizo Fabiola Jesavel Flores Nava, quien trató de explicar dicha categoría únicamente desde una revisión documental parcial (2016). Por lo tanto, esta intelectual caracteriza al antisistema de la siguiente manera:

- Territorio, administración y organización propia. Por ello, la investigadora ejemplifica el caso zapatista en el que ella dice que el "territorio zapatista, la organización política y administrativa del gobierno autónomo está compuesta por tres conjuntos de autoridades que ejercen sus funciones en sus respectivos niveles de gobierno -comunidad, municipio y zona-, sin que esto quiera decir que haya límites o fronteras territoriales absolutos entre uno y otro ámbito. En los gobiernos autónomos no encontramos esa distancia que por su dominio y disfrute de privilegios hace ajenos del resto de la población a los gobernantes; tampoco hay una "división de poderes” entre Ejecutivo, Legislativo y Judicial; ni una distribución de responsabilidades en función de conocimientos parciales, supuestamente separados por especialidades" (2009).

- La asamblea como espacio de producción de la política comunitaria. En este caso, es importante recuperar una cita de la autora en la que menciona que "la comunicación y la colaboración entre las autoridades autónomas para tratar cualquier asunto son prácticas continuas que facilitan la participación de los pueblos enteros, sea ocupando temporalmente cargo por elección en alguna instancia de gobierno, sea participando en las decisiones y acuerdos que se toman en la Asamblea general de la comunidad, que es la base de toda autoridad” (2009).

- La elección de autoridades y la definición de cargos políticos. Según Fernández Christlieb, la rotación y distribución de cargos es la base de la politización comunitaria para crear la voluntad colectiva. Ella explica que "el proceso de selección y de elección de las autoridades autónomas en sus diferentes ámbitos y niveles de gobierno, las propuestas y resultados pasan siempre por la Asamblea General del pueblo, lo que significa que las autoridades zapatistas surgen de las comunidades, son bases de apoyo, compañeros civiles que no forman parte de la estructura militar” (2009).

Precisamente, si se hace un análisis sobre lo anterior, esta separación de los gobiernos civiles y el brazo armado, que es el ejército zapatista, es parte 
de la construcción tanto de la autonomía en municipios y comunidades, como de la democratización de los cargos y sus procesos de elección.

- Por último, la categoría de antisistema político. Según Fernández, esta explica esas experiencias que se basan en una ética y valores políticos guiados por la idea de que el bien común es punto de partida y llegada para el desarrollo comunitario. Cuestión que distingue a este antisistema del sistema político mexicano y de otros que siguen esta lógica. Por ello, la politóloga expresa que "a diferencia de quienes en el sistema político mexicano aspiran a los cargos públicos oficiales porque los ven como una oportunidad de enriquecimiento personal, rápido, fácil, y con cobertura legal, o como una garantía de ascenso social que con solo pasar de un puesto a otro les asegure poder irse y nunca más volver al pueblo, al ejido, al barrio, al lugar de donde salieron; o como un medio de acumulación de poder político que pretenden ejercer más allá del periodo que duren en el cargo” (2009).

Tanto antisistema político como autonomía son útiles no solo como categorías analíticas, sino también como indicadores para caracterizar a las izquierdas actuales, en especial, la relación entre las luchas sociales y las ideologías que se producen y formulan los intelectuales que se adscriben a estas. Por lo tanto, las luchas por la autonomía y la democratización desde los márgenes del Estado se han convertido en una tendencia de las luchas y reivindicaciones de la izquierda mexicana antisistémica y las latinoamericanas.

\section{Debates y conclusiones}

Después de haber revisado 43 textos totales, en los que se identificaron 8 escritos de la investigadora mexicana y el resto de fuentes de contexto y referencias teóricas y documentales, se llega a la conclusión de que el pensamiento de profesionales en esta orientación, por un lado, aporta un importante debate sobre los paradigmas y centros conceptuales que se toman, como punto de partida, para analizar a la ciencia política actual. El debate consiste en pensar si la disciplina actual debe limitar su marco conceptual a las políticas públicas y la democracia electoral o también debe ampliar su horizonte teórico y ser sensible al análisis de los movimientos sociales y otras experiencias de lucha por el poder desde los márgenes y subsuelos de México y América Latina.

Por otra parte, aunque la politóloga mexicana formuló su pensamiento a partir de un estudio de caso, como el zapatista, y no consideró otras experiencias 
latinoamericanas de lucha y debates de izquierda en otros países, como el caso de Colombia, en las que dicho término no tiene el mismo significado que en México, sí logró proponer, de manera efectiva, a la autonomía y la discusión antisistémica, que actualmente permiten diferenciar a las ideologías de izquierda de las derechas.

Por lo tanto, el pensamiento investigativo de Paulina Fernández Christlieb puede calificarse como alternativo, en el sentido que propone pensar a la ciencia política desde otros marcos contextuales y conceptuales, como las experiencias de las movilizaciones sociales y la izquierda, pero, al mismo tiempo, sus ideas no consideraron que también hay luchas y organizaciones que tienen dinámicas al margen del Estado y que no necesariamente se adscriben a una ideología rebelde o propiamente de izquierda. Finalmente, hay que destacar que esta académica, en México, fue un ejemplo de esfuerzo por la congruencia política y el desarrollo de la investigación en las universidades, porque continuamente practicó su compromiso con los sujetos estudiados, como fue el caso del zapatismo.

Su compromiso llegó a tal punto, que en su etapa final investigativa y de vida, se adentró y formó parte de la organización política del zapatismo, sin dejar de escribir sobre las características de los fenómenos relacionados con la autonomía, el autogobierno y los debates ideológicos de una izquierda incapaz de mantener sus principios cuando asume el poder político en países como México, y en varios casos latinoamericanos.

\section{Referencias}

Aguirre Rojas, C. A.. (2018). Movimientos antisistémicos y la cuestión indígena en América Latina. Una visión desde la larga duración histórica. Santiago de Chile: Quimantú.

Anguiano, A.. (2016). Paulina Fernández Christlieb. (2014). Justicia autónoma zapatista. Zona Selva Tzeltal, México: Estampa / Ediciones Autónom@s. Recuperado de http://www.scielo.org.mx/scielo.php?script=sci_arttext\&pid=S1870392520160003 $00347 \&$ lng $=$ es\&tlng =es.

Ávila Rojas, O. (2018). La experiencia zapatista. Análisis sobre sus prácticas democráticas. Revista de Ciencias Sociales del Departamento de Ciencias Sociales de la Universidad de la República de Uruguay, 31 (42), pp. 177-194. Recuperado de http://cienciassociales.edu.uy/departamentodesociologia/wpcontent/uploads/ sites/3/2014/06/Revista-N\%C2\%BA-421.pdf.

Ávila Rojas, O. (2019). El sujeto zapatista y su proyecto político. Revista Civilizar de Ciencias Sociales y Humanas de la Universidad Sergio Arboleda, 19 (37), pp. 1-20. https://doi.org/10.22518/usergioa/jour/ccsh/2019.2/a02. 
Ávila Rojas, O. (2020). El indígena desde el zapatismo: un caso de centralidad política del indio. México: Quinto Sol.

Bobbio, N. \& Matteucci, N. (1985). Diccionario de política. México: Siglo XXI.

Bobbio, N.. (1995). Derecha e izquierda. Razones y significados de una distinción política. Madrid: Taurus.

Cavarozzi,M.(1992). Beyond Transitions to Democracy in Latin America, Journal of Latin American Studies, 24 (03), pp. 665-684.

Comité Clandestino Revolucionario Indígena \& Comandancia General del Ejército Zapatista. (2000). Declaración de la Selva Lacandona. En Ejército Zapatista de Liberación Nacional, Declaraciones de la Esperanza (pp. 9-11). México: FZLN.

Comité Clandestino Revolucionario Indígena \& Comandancia General del Ejército Zapatista. (2000a). Segunda Declaración de la Selva Lacandona. En Ejército Zapatista de Liberación Nacional, Declaraciones de la Esperanza (pp. 12-19). México: FZLN.

Comité Clandestino Revolucionario Indígena \& Comandancia General del Ejército Zapatista. (2000b). Tercera Declaración de la Selva Lacandona. En: Ejército Zapatista de Liberación Nacional, Declaraciones de la Esperanza (pp.20-25). México: FZLN.

Comité Clandestino Revolucionario Indígena \& Comandancia General del Ejército Zapatista. (2000c). Cuarta Declaración de la Selva Lacandona. En Ejército Zapatista de Liberación Nacional, Declaraciones de la Esperanza (pp. 26-35). México: FZLN.

Comité Clandestino Revolucionario Indígena \& Comandancia General del Ejército Zapatista. (2005). Sexta Declaración de la Selva Lacandona. En Rebeldía, pp. 1-20. México: Editorial Rebeldía.

Fals Borda, O.. (2019). Campesinos de los Andes y otros escritos antológicos. Bogotá: Universidad Nacional de Colombia.

Fernández Christlieb, P. (1978). El espartaquismo en México. México: El Caballito.

Fernández Christlieb, P. (2003). El EZLN y la GBI en Chiapas: derechos indígenas contra corporaciones trasnacionales. Lancaster: Manheim.

Fernández Christlieb, P. (2006). Crisis de la democracia electoral. México: IIS-UNAM.

Fernández Christlieb, P. (2009). Gobierno autónomo zapatista: características del antisistema político mexicano. En Chiapas: Enlace Zapatista. Recuperado de: http://enlacezapatista.ezln.org.mx/2010/02/15/gobierno-autonomo-zapatistacaracteristicas-antisistema-politico-mexicano/.

Fernández Christlieb, P. (2012). Justicia autónoma frente a justicia oficial. Estudios Políticos de la Universidad Nacional Autónoma de México. (26), pp.37-55. Recuperado de http://www.scielo.org.mx/scielo.php?script=sci_arttext\&pid=S0185161620120002 $00003 \& \operatorname{lng}=e s \&$ tIng=es.

Fernández Christlieb, P. (2014). Justicia autónoma zapatista en la Zona Selva Tseltal. México: Estampa-Ediciones Autónom@s.

Fernández Christlieb, P. \& Rodríguez Araujo, O. (1985). La clase obrera en la historia de México en el sexenio de Tlatelolco (1964-1970). Madrid: Siglo XXI.

Fernández Christlieb, P. \& Sirvent, C. (2001). La marcha del EZLN al Distrito Federal. Chiapas: UNAM.

Flores Nava, F. J.. (2016). Los pasos hacia la autonomía indígena en México. La autonomía como concepto antisistémico. En Ramírez Zaragoza, Miguel Ángel (coord). Movimientos sociales en México: apuntes teóricos y estudios de caso, pp. 205223. México: UAM-Azcapotzalco- Red Mexicana de Estudios de los Movimientos Sociales. 
Hernández, S., Guerrero, G. \& Tobón, S. (2015). Los problemas del contexto: base filosófica y pedagógica de la socioformación. Revista Ra Ximhai de la Universidad Autónoma Indígena de México. 11. (4), pp. 125-140. Recuperado de https://www. researchgate.net/publication/289379549_Los_problemas_del_contexto_base_ filosofica_y_pedagogica_de_la_socioformacion.

Gallardo, H.. (2007). Democratización y democracia en América Latina. Bogotá: Desde Abajo.

Gaudichaud, F., Webber, J. \& Modonesi, M.. (2019). Los gobiernos progresistas latinoamericanos del siglo XXI: ensayos de interpretación histórica. México: UNAM.

Gramsci, A. (1980), Cuadernos de la cárcel: notas sobre Maquiavelo, sobre política y sobre el Estado moderno. Tomo I. México: Juan Pablo Editores.

López Leyva, M. A.. (2012). Los movimientos sociales y su influencia en el ciclo de las políticas públicas. Revista Región y Sociedad, 24(55), 159-197. Recuperado de http://www.scielo.org.mx/scielo.php?script=sci_arttext\&pid =\$1870392520120003 00005\&lng=es\&tlng=es.

Mariátegui, J.C. (2007). Siete ensayos de interpretación de la realidad peruana. México: Era.

Marx, K. y Engels, F.. (2007). El manifiesto del Partido Comunista. México: Fondo de Cultura Económica.

Marx, K.(2017). El capital. Tomo I. México: Siglo XXI Editores.

Melucci, A.. (1999). Acción colectiva, vida cotidiana y democracia. México: El Colegio de México.

O Donnell, G. \& Schmitter, P.. (1986). Tentative Conclusions about Uncertain Democracies. En O Donnell, G.A.Schmitter, P. \& Whitehead, L. (Eds.). Transitions from Authoritarian Rule: Prospects for Democracy, pp.115-130. Baltimore: Johns Hopkins University Press.

Osorio, J.. (2015). El sistema-mundo de Wallerstein y su transformación: una lectura crítica. Revista Argumentos de la UAM Xochimilco. 28(77), pp. 131-154. Recuperado de http://www.scielo.org.mx/scielo.php?script=sci_arttext\&pid=S0187579520150 00100007\&lng=es\&tlng=es.

Ostrom, E. (2010). Elección racional institucional. Evaluación del marco del análisis y desarrollo institucional, En Sabatier, Paul (ed.), Teorías del proceso de las políticas públicas, (pp. 23-66). Buenos Aires: Westview Press.

Petrich, Blance. (5 de marzo de 2020). Adiós a Paulina Fernández Christlieb, analista clave para ver ese otro México. La Jornada.

Pleyers, G.. (2018). Movimientos sociales en el siglo XXI: perspectivas y herramientas analíticas. Buenos Aires: CLACSO.

Roth Deubel, A.N. (2002). Políticas públicas: formulación, implementación y evaluación. Bogotá: Aurora.

Tarrow, S.. (1997). El poder en movimiento. Los movimientos sociales, la acción colectiva y la política. Madrid: Alianza.

Vélez Rivera, R. A. (2015). Ciencias sociales, movimientos sociales y políticas públicas. Revista El Ágora U.S.B., 15(2), pp. 515-533. Recuperado de http://www. scielo.org.co/scielo.php?script=sci_arttext\&pid =S165780312015000200011\&lng= en\&tlng=es.

Wallerstein, I. (2005). Análisis de sistema- mundo. Una introducción. México: Siglo XXI.

Zavaleta Mercado, R. (1990). El Estado en América Latina. La Paz: Los Amigos del Libro.

Zavaleta, R.. (2008). Lo nacional-popular en Bolivia. La Paz: Ediciones Plural. 